\title{
Journal of Contemporary Medical Sciences
}

\section{Allocating Resources in Health Care Services}

Jaffar Allawi

Consultant Endocrinologist Diabetologist - Queen Mary's Hospital - St Georges Hospital Teaching,

Roehampton Lane, London SW15 5PN, United Kingdom. (email: jaffar.allawi@stgeorges.nhs.uk).

\section{LETTER TO EDITOR}

\section{Dear Editor-in-cheif}

This paper helps to find best methods for improving and rehabilitating health services in Iraq. It is not meant to be comprehensive but to stimulate the reader to consider the importance of allocation of resources appropriately, to encourage the development of research programs, data collection, computerisation, and data analyses and to implement best methods to allocate financial and human resources.

Having stated the aims of this letter one needs to consider the:

1. background of this work,

2. strategy and

3. tactics to be implemented to achieve our goals.

If we take the definition of Health by the World Health Organisation in its broader sense in its 1948 constitution as 'a state of complete physical, mental, and social well-being and not merely the absence of disease or infirmity', and the Definition of Health Resources Allocation, which states that all materials, personnel both teaching and care providers, medical facilities, funds, and anything else that can be used for providing health care and services, then we would understand the importance of resource allocation.

\section{Background of Health Services in Iraq}

Since the opening of the first medical school, The Royal College of Medicine "Al-Albeit University of Iraq" in the 20s of last century by the British, occupiers of Iraq, and followed many years later by Mosul Medical School as well as the School of Nursing. Iraqi Health Services, which is a mix of National Health and Private Medical Services. Iraqi Hospitals continued to improve from the 20s until 1958. Unfortunately, following the revolution of 1958, the health services went between development and decay. The latter was prominent in the late 70s when the Iraqi Government interfered with the teachings of medicine by expelling high calibre teachers from the medical schools. In addition, the other degrading factor was recruiting the newly graduate doctors led to many wars as privates. These untrained junior doctors suffered a lot of psychological and health ailments. The level of the medical schools and training deteriorated to unacceptable levels. The National Health hospitals due to lack of appropriate management and corruption paid heavily. After the 2003 US occupation of Iraq, the Iraqi health services received its final knock out with unprecedented corruption in all aspects of health services. ${ }^{2}$ There was also destruction to major pharmaceutical industries in Samara and Mosul. The damage to infrastructure, training of doctors and nurses at the under and postgraduate levels, the standards of hospitals, has led to serious health care issues.

\section{Health Care Resources in Iraq}

All National Health Government hospitals are built and financed by the Iraqi Government. Individual/s investors are the main financers for the private sector hospitals. The latter has mushroomed in numbers before the American occupation in 2003. Following the occupation, many private hospitals were either sold to other investors or closed. The Iraqi Government has an allocation of funds for new hospitals together with their supply of equipment and maintainance. Also, there are many religious organisations like al Attabh al Hussainiah and al Abbassia, which have invested in nonprofit making hospitals in different parts of Iraq. Then, trained personnel required for these hospitals were appointed. Unfortunately, the latter has not been adequately addressed, i.e. the level of experience and training. An important fact should be mentioned here is the number of doctors, dentists, pharmacists who are highly qualified, well trained who work in Europe, US, and England has increased. The number of these medical personnel is estimated to be over 30,000. A serious improvement to health care is to consider repatriation but off course at a cost. ${ }^{3}$

\section{The Strategy to Improve Health Care Services in Iraq}

From the definition stated earlier, one needs to allocate the right sum of funds to the needs of the health care service whether teaching or otherwise. The funds and requirements are almost always not clear in Iraq due to insufficient data provided by the Ministry of Health. Therefore, it is paramount that data should be collected and analysed to prepare the application for funds correctly. It is well known that well-informed people make better decision:

1. Collecting data, entering a capable data base, storing data preferably in cloud storage, securing the data with passwords and antiviral software.

2. The data should be cleaned and entered using a statistical package like BMDP, SAS, SPSS, and STATA.

3. High calibre and well-trained statisticians should analyse the data to be informative to give idea of i) number of population, ii) male-female ratios, iii) age quartiles, iv) disease prevalence, $v$ ) population of urban rural or both and finally vi) what type of medical care services can be provided. 


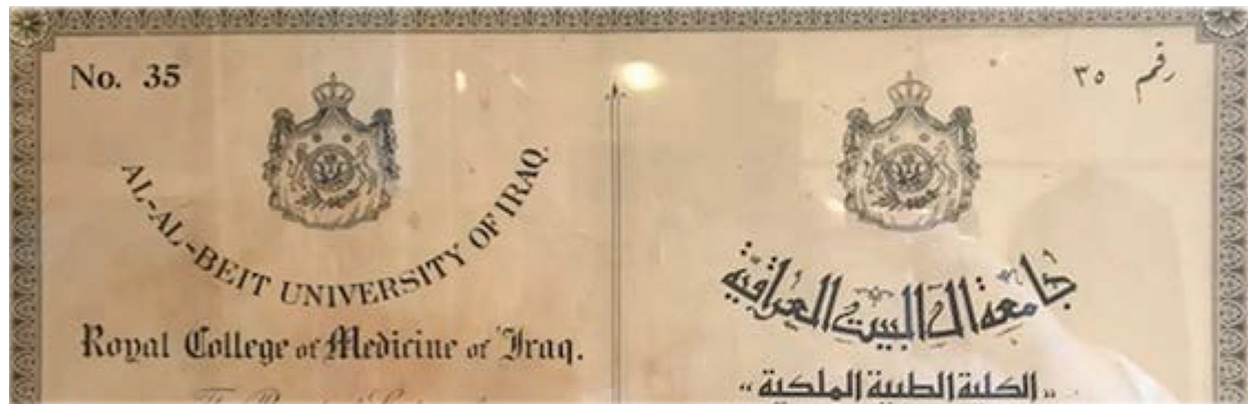

Fig. 1 The University Insignia.

\section{Preparation for Application for Funds for a Medical Service/s}

One needs to study populations and their needs for care by arranging epidemiologic survey methods, such as home to home data collection, school pupils, private companies, and government offices including police and military. A detailed analysis on the collected data can be done as pilot studies to start with the help of medical students and nurses. Following pilot studies, one can start a more comprehensive data collection for larger cohort. Prevalence of disease and its management can help to establish costs of doctors and nurses point of care and follow up care as well as costs of medications. This would be ideal for chronic conditions like hypertension, diabetes, rheumatoid arthritis and chronic kidney disease as an example.

\section{Teaching Doctors, Dentists, Pharmacists, and Nurses}

On repeated visits to Iraq and meeting the new generation nurses and doctors, one feels the big gap between older education and training. The recent graduates training and level of education are not adequate that can be easily noticed. Also, the management of medicines in private hospitals is not appropriate. Most medicines have unknown source of manufacturing and expiration is doubtful. In this setting, it is very important to establish recertification, appraisal, and revalidation annual exams for all personnels in medical practice including dentists, pharmacists, nurses and tetanisations. Funds should be allocated for this purpose.

\section{Hospitals and Medical Institutions}

Almost all hospitals in Iraq need extreme rehabilitation and maintenance. These institutions lack modernisation and proper setting for managing patients. They are also very poorly equipped and standard of cleanliness and hygiene is again questionable. Here, again the need of improvement is paramount. Allocation of

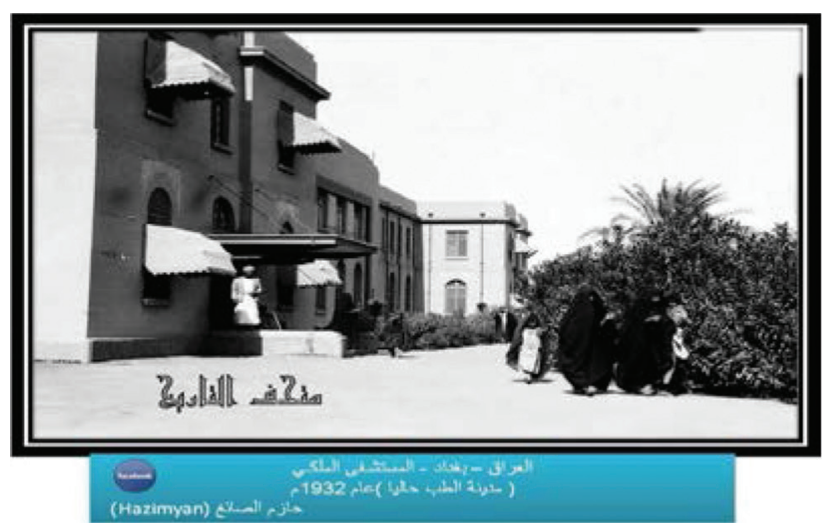

Fig. 2 Al Majediah Hospital 1930 - later the Royal Hospital.

funds to improve may require employing European or American management organisations and part of these contracts should aim at training Iraqi personnel.

\section{Allocating Resources}

From the above, the Iraqi Government and the Ministry of Health with the help of Ministry of Finance and banks should prepare holistic feasibility studies, project management and time and allocation of resources. Extreme penalties on contractors should be implemented on non-performing contractors. The help of many European and US Government is available if the will of the Iraqi's to help themselves is established.

\section{Conclusion}

Iraq health services continued to deteriorate for many years now it has reached its nadir. Efforts of doctors, banks, Ministry of Health, Universities with active teams should plan a strategy to improve the ailing health services in Iraq. Allocation of funds towards effective service is the responsibility of all Iraqis and not just the Government of Iraq.

\section{References}

1. Iglehart, John K. Revisiting the Canadian Health Care. New Engl J Med. 2000;342:2007-2012

2. Albujeer AN, Taher A. Dental education and oral health service in Iraq. Iranian J Pub Health. 2017;46: 713-714.

3. Resource Allocation in Healthcare: implications of models of medicine as profession. Eileen-HennerW. Kluge,PhD @ www.medscape.com

4. Detsky AS, Stricker SC, Mulley AG, Thibault GE. Prognosis, survival and the expenditure of hospital resources for patients in an intensive care unit. N Eng J Med. 1981;305:667-672.

This work is licensed under a Creative Commons Attribution-NonCommercial 3.0 Unported License which allows users to read, copy, distribute and make derivative works for non-commercial purposes from the material, as long as the author of the original work is cited properly. 